\title{
Projeto de extensão de Pilates na percepção corporal de universitários: estudo qualitativo
}

\author{
Qualitative study: Pilates on body's perception of college students
}

\section{Samara Martins de Oliveira Souza', Brena Costa de Oliveira' ${ }^{2}$, Cibelle de Sousa e Silva ${ }^{3}$, Letícia Graziela Lopes França Sousa ${ }^{4}$, Valéria Monteiro Beserra da Silva ${ }^{5}$, Stephanie Sarah Cordeiro de Paiva ${ }^{6}$, Michelle Vicente Torres ${ }^{7}$}

${ }^{1}$ Autora para correspondência. Universidade Estadual do Piauí. Teresina, Piauí, Brasil. ORCID: 0000-0002-8088-8817. samaramartins10@hotmail.com 2Universidade Estadual do Piauí. Teresina, Piauí, Brasil. ORCID: 0000-0002-2352-6342. brena_oliveira.5@hotmail.com 3Universidade Estadual do Piauí. Teresina, Piauí, Brasil. ORCID: 0000-0001-5715-5407. cibellycaldas@hotmail.com ${ }^{4}$ Universidade Estadual do Piauí. Teresina, Piauí, Brasil. ORCID: 0000-0002-9977-8933. I_graziela@hotmail.com 5Universidade Estadual do Piauí. Teresina, Piauí, Brasil. ORCID: 0000-0002-6070-6748. lerinha0609@hotmail.com

6Universidade Federal do Piauí. Teresina, Piauí, Brasil. ORCID: 0000-0001-6349-4691. stephanie.aus@hotmail.com 7Universidade Estadual do Piauí. Teresina, Piauí, Brasil. ORCID: 0000-0001-5084-228X. michellevicento@yahoo.com.br

RESUMO I INTRODUÇÃO: O método Pilates promove um equilíbrio entre o corpo e a mente, trabalhando o ser humano integralmente, exigindo de quem o pratica uma percepção também do que acontece no meio em que vive. OBJETIVOS: Avaliar a contribuição de um projeto de extensão abordando o método Pilates na aprendizagem sobre o conceito e percepção de corpo de acadêmicos de Fisioterapia de uma universidade pública. MATERIAIS E MÉTODOS: Trata-se de uma pesquisa prospectiva, qualitativa, observacional e analítica, contendo uma amostra de oito acadêmicos de Fisioterapia de uma instituição pública da cidade de Teresina-Piauí, participantes do projeto de extensão com aplicação de práticas corporais baseadas no método Pilates. Os participantes foram entrevistados no período de maio de 2018, mediante entrevista semi-estruturada, composta por perguntas relativas ao conceito e percepção de corpo. RESULTADOS: Após serem analisadas as falas dos acadêmicos, surgiram duas categorias temáticas a serem discutidas: Pilates na percepção de corpo e as possibilidades do corpo. CONCLUSÃo: Atividades de extensão em Pilates contribuem positivamente para o conceito e percepção de corpo de acadêmicos do curso de Fisioterapia.
ABSTRACT | INTRODUCTION: The Pilates method promotes a balance between body and mind, working the whole human being, demanding from those who practice it a perception of what happens in the environment. OBJECTIVES: To evaluate the contribution of a project that deals with the Pilates method in the learning process of the concept and body perception of physiotherapy students from a public university. MATERIALS AND METHODOLOGY: It is a prospective, qualitative, observational and analytical research. The study was conducted with a sample of eight physiotherapy students from a public institution in the city of Teresina-Piauí. The students were participants of the project with the application of body practices based on Pilates method. Participants were interviewed in May 2018 through a semistructured interview, consisting of questions regarding the concept and body perception. RESULTS: After analyzing the students' speeches, two themes came up: Pilates in body perception and body possibilities. CONCLUSION: Pilates extension activities contribute positively to the concept and body perception of physiotherapy students.

KEYWORDS: Pilates. Body image. Academic students.

PALAVRAS-CHAVE: Pilates. Imagem corporal. Acadêmicos. 


\section{Introdução}

A imagem corporal é a figura do nosso próprio corpo que desenhamos em nossa mente, ou seja, o modo pelo qual o corpo se reflete para nós mesmos ou como o vivenciamos ${ }^{1}$. Sabe-se que a imagem do corpo é um processo constante e ativo que permanece durante toda a vida e envolve características fisiológicas, afetivas e sociais que interagem entre si a todo instante ${ }^{2}$. Neste sentido, a construção imaginária contemporânea de um corpo perfeito ou ideal, muitas vezes está intimamente associada a um discurso obsessivo da saúde³.

Para Bomfim 4 , é necessário que o ensino acadêmico anexe em seu currículo práticas sobre o corpo, propondo uma visão total do ser humano, respeitando as motivações e sentimentos como parte do processo ensino-aprendizagem. Estas práticas devem ser consideradas como dinâmica de sala de aula diversificando as experiências. Dessa forma, se faz necessário na formação profissional a construção de uma visão globalizada do ser humano, não o vendo apenas partes do corpo. É necessário ver, sentir e experimentar a totalidade em que corpo, sentimento, hábito cultural e meio ambiente fazem parte da reabilitação física do paciente ${ }^{5}$.

O método Pilates está sendo cada vez mais difundido e praticado pelo mundo todo. Um dos motivos desta aderência é os seus inúmeros benefícios a partir da prática frequente deste método. Dentre os benefícios, podemos citar: fortalecimento do corpo (especialmente da musculatura do abdômen), melhora no alongamento e da flexibilidade, desenvolvimento da consciência corporal, melhora da coordenação, da postura, do equilíbrio, aumento da mobilidade articular, desenvolvimento dos músculos estabilizadores da coluna e alívio de dores crônicas ${ }^{6}$.

Segundo Souza ${ }^{6}$, este método promove um equilíbrio entre o corpo e a mente, trabalhando o corpo na sua integralidade, exigindo de quem o pratica uma percepção também do que acontece no meio em que vive. Ou seja, as pessoas também conseguem analisar como o meio pode influenciar nas tensões provocadas no ambiente em que se vive. Além de integrar o corpo e a mente, se torna mais fácil perceber o ambiente ao redor.
Para Pires e Sá7, por meio do Pilates, o aluno finalmente vai conhecer e aprender a usar de forma correta o próprio corpo, pela conexão entre corpo e mente. No entanto, é pouco conhecido seu efeito em acadêmicos de fisioterapia que se preparam para a atuação profissional sobre o corpo do outro. Este fato justifica a importância do estudo, uma vez que através da concentração, o praticante pode sentir o movimento de forma intensa e desenvolver autoconhecimento e respeito ao próprio corpo ${ }^{8}$. É provável que isto o prepare melhor para cuidar do corpo do outro.

Diante do exposto, o objetivo foi avaliar a contribuição de um projeto de extensão abordando o método Pilates na aprendizagem sobre o conceito e percepção de corpo de acadêmicos do curso de fisioterapia de uma universidade pública.

\section{Metodologia}

Trata-se de uma pesquisa prospectiva, de abordagem qualitativa, observacional e analítica. A amostra foi do tipo intencional constituída por acadêmicos do curso de fisioterapia de uma instituição pública da cidade de Teresina-Piauí, participantes do projeto de extensão com aplicação de práticas corporais baseadas no Método Pilates intitulado "USO DO PILATES PARA MELHORA DA QUALIDADE DE VIDA DE ESTUDANTES DA UNIVERSIDADE ESTADUAL DE TERESINA-PI".

A seleção dos estudantes para a participação do projeto de extensão ocorreu de forma aleatória. Foram abertas inscrições, contendo 15 vagas, para todos os acadêmicos do curso de fisioterapia, do primeiro ao décimo período. As vagas foram sendo preenchidas à medida que as inscrições foram realizadas, até completar a quantidade pré-estabelecida.

O projeto de extensão do método Pilates teve duração de seis meses, ocorrendo no período de outubro de 2017 a abril de 2018, duas vezes na semana (segundas e quintas), com duração de uma hora. As práticas foram executadas por acadêmicos do curso de Fisioterapia, coordenados por um docente, onde estes foram previamente orientados com aulas teóricas iniciais sobre os princípios do método Pilates. 
As práticas foram realizadas em sala, utilizando colchonetes, sendo um para cada participante, e caixa de som para ambientação do local com música adequada (especificar?)

Os exercícios realizados foram focados em alongamentos e fortalecimentos, sendo eles: spine strech (alongamento posterior), roll up (rolamento para cima); roll over (rolamentk por cima); roll like a ball (balanço com a coluna); double leg strech (alongamento das duas pernas); swimming (extensão); saw (serrote); side bend (flexão lateral); spine twist (torção da coluna); the hundred (cem); the shoulder bridge (ponte); high one leg bridge (ponte com a perna elevada); criss-cross (oblíquos); mermaid (sereia), prancha isométrica, entre outros.

A pesquisa foi analisada e aprovada em 15 de maio de 2017 pelo Comitê de Ética e Pesquisa sob o número de CAAE 67139317.2.0000.5209, seguindo os padrões éticos de acordo com a resolução 466/12 do Conselho Nacional de Saúde. Os estudantes selecionados para a pesquisa assinaram o Termo de Consentimento Livre e Esclarecido - TCLE, garantindo o sigilo total da identidade dos participantes, o esclarecimento sobre quaisquer dúvidas sobre a pesquisa, bem como o aceitar como também a recusa na participação da mesma.

Para que os dados fossem coletados os estudantes foram abordados no término do projeto de extensão de Método Pilates, e posteriormente, agendado o local e horário para a realização das entrevistas. Os participantes foram entrevistados mediante entrevista semi-estruturada, composta por perguntas sobre sua visão de corpo. As perguntas norteadoras foram:

1. Esse projeto de extensão ajudou você de alguma forma a perceber o seu corpo? Fale sobre isso.

\section{O que pode o corpo? Fale sobre isso.}

Os dados foram analisados conforme a Análise de Conteúdo proposta por Bardin (2004), que possibilita a interpretação cifrada do material de caráter qualitativo.
As entrevistas ocorreram no período de maio de 2018, na própria instituição onde ocorreu o projeto de extensão, respeitando a disponibilidade dos entrevistados. As perguntas foram feitas presencial e individualmente. Os dados foram gravados pelo pesquisador, utilizando-se um gravador de voz digital (Smartphone Samsung J5 Metal). Em seguida, os áudios foram transcritos na íntegra para o computador, possibilitando uma melhor análise do conteúdo. Ademais, o material coletado passou por correções linguísticas, sem eliminar o caráter natural das falas.

\section{Resultados}

Inicialmente a amostra foi composta por 15 estudantes do curso de fisioterapia, porém houveram 7 desistências, restando 8 acadêmicos, sendo 7 do sexo feminino e 1 do sexo masculino. Após a análise das falas dos acadêmicos, surgiram duas categorias temáticas a serem discutidas: Pilates na percepção de corpo que teve como conceito "O Pilates promove um equilíbrio entre o corpo e a mente, trabalhando o corpo na sua integralidade" e As possibilidades do corpo, que teve como conceito "O corpo é o lugar onde há a quebra da simetria, onde tudo pode acontecer e acontece".

Foi observado uma ampliação da percepção do próprio corpo exemplificada nos relatos:

“...eu percebo que eu posso mais coisa, posso fazer mais coisa do que eu podia fazer antes. Eu acho que o Pilates me ajudou muito a perceber isso." (Copo de Leite)

"Eu tinha muitas limitações antes de começar, ai ao longo do processo eu fui tanto conhecendo realmente o meu corpo e sabendo como usar ele tendo mais facilidade pra fazer as atividades em si." (Orquídea)

"...me fez trabalhar músculos que eu não conhecia a função. Senti a força que eu tinha e eu consegui trabalhar melhor isso." (Lótus)

A partir da análise das falas foi notável que a prática do método Pilates proporcionou aos estudantes momentos de relaxamento, diminuição do estresse emocional e tensão corporal, atuando sobre a saúde mental deles, como relatado nas falas de Rosa e Tulipa: 
Quando eu vinha fazer os exercícios eu tipo... meu corpo ele mudava, às vezes eu tava estressada, assim, eu tava super tensa, depois que vinha e fazia um exercício eu saia mais relaxada... (Rosa)

Eu sou uma pessoa muito estressada, muito estressada e às vezes quando eu venho pra cá eu fico só, eu tenho muito assunto para estudar, aquela coisa toda. Toda aquela pressão da universidade. $E$ às vezes quando eu chego aqui eu saio bem mais leve...(Tulipa)

Foi verificado que as vivências nesse grupo constituíram um momento de prazer e de autoconhecimento, de resgate da importância e do autocuidado, por meio de atividades para melhorar a sua saúde e trazer-lhe bem-estar, conforme mostrado nos fragmentos a seguir, extraídos dos discursos dos entrevistados:

Porque assim, eu vou falar de uma forma meio grosseira, antes eu era meio desleixada, e esse projeto me estimulou muito a me cuidar mais entendeu? A ter uma percepção melhor da minha saúde pra... tipo assim... cuidar de mim...(Tulipa)

Ajudou a perceber que eu sou muito encurtada, mas também ajudou a trabalhar mais meu corpo, a trabalhar o alongamento do meu corpo. E perceber que o exercício é bom pro meu corpo e que eu preciso continuar isso...(Margarida)

Percebi que eu preciso, que eu tenho que me cuidar entendeu? Depois que eu entrei aqui me estimula mais a praticar exercício, a ter uma alimentação melhor. Porque conciliar isso é muito importante pro bom funcionamento do organismo e do corpo...(Rosa)

A presente categoria traz as percepções dos participantes do projeto de extensão a respeito das possibilidades do corpo, os limites que ele pode atingir, sua mutabilidade e capacidade de transmitir sentimentos, além da interação corpo e mente no sucesso da execução dos movimentos.

O corpo quando treinado é capaz de chegar a pontos jamais imaginados, ele age de acordo com o estímulo dado a ele, podendo o ser humano estar sempre superando seus limites. A capacidade do corpo e seu poder de mutabilidade impressionaram os estudantes que de acordo com as práticas corporais puderam ressignificar seus conceitos sobre si mesmos, podendo conseguir realizar exercícios que se julgavam incapazes. Isso pôde ser evidenciado nas duas falas em destaque:

Assim, eu acho que ele é capaz de evoluir, como eu já falei de se superar, de mudar, de aceitar novos limites, novas coisas, de se adaptar também a novos ambientes, novas atividades... (Copo de leite)

É só uma questão de tipo assim, preparação, uma questão de... como é que eu posso dizer... é preparação entende, porque não é só querer, eu também tenho que preparar ele pra aquilo pra ele poder executar o que eu tiver, o que eu quiser que ele faça entendeu?...(Tulipa)

Os estudantes podem ter compreendido que a capacidade de seus corpos se dá através dos limites impostos pelas suas mentes, como visto nas falas de Girassol e Tulipa:

O corpo eu acho que ele age de acordo com a sua mente também. E aqui no pilates com a concentração você pode fazer além do que você acha...(Girassol)

Ele pode tudo que eu tipo assim, não que eu propor ele a fazer, o que eu tiver determinada a fazer entendeu? Se eu quiser superar os meus limites meu corpo vai fazer isso. Ele vai me ajudar a fazer isso, ele tem a capacidade, eu tenho a capacidade, eu sou capaz e meu corpo pode tudo que eu tiver determinada a fazer, tudo que eu impor ele...(Tulipa)

Há uma linha tênue entre corpo e mente, sendo o corpo capaz de transcender o físico aparente. Essa característica do corpo interfere no modo de agir e de se portar frente às atividades de vida diária, incluindo à prática de exercícios, como as que foram propostas no projeto de extensão.

Isto pôde ser observado pelos participantes, já que possivelmente puderam sentir que nos momentos em que apresentavam dificuldades curriculares ou extracurriculares, isso podia interferir na evolução dos exercícios propostos, como visto na fala abaixo: 
O meu corpo transmite tudo o que tem dentro de mim, o que eu estou sentindo, passando, pensando e vivendo. Ele é o espelho da minha alma, do meu ser, ele... não sei.

Ele é minha imagem, ele é o que eu to vivendo, que eu to passando. Por exemplo, se um dia eu tô bem triste, jogada, desleixada, o meu corpo vai transmitir isso, as minhas características físicas vão transmitir isso... (Tulipa)

Os estudantes puderam ter o sentimento de autocuidado, já que ao realizar os exercícios pareceram ter a percepção de estar fazendo o bem a si mesmo, e que a partir desse cuidado poderiam estar preparados para as atividades da vida. Isso pode ser evidenciado na fala em destaque:

O corpo pode tudo. Acho que um bom funcionamento do corpo é a base de tudo, tanto pra gente principalmente no trabalho e na vida em si. Pra tudo, acho que você não consegue realizar nada se você não tiver um bom funcionamento do seu corpo...(Orquídea)

\section{Discussão}

\section{Pilates na Percepção de Corpo}

Nesta categoria é possível observar que os participantes do estudo ampliaram o pensamento que tinham a respeito do próprio corpo a partir das reflexões advindas da experiência corporal por meio do Pilates. Por ser uma atividade que requer concentração e boa administração dos movimentos e respiração, o Pilates acaba sendo capaz de despertar em seus praticantes um estado de atenção que permite a ampliação da percepção do movimento corporal. Esse estado de contemplação do seu próprio eu, propicia aos entrevistados um momento de autoconhecimento e autocuidado.

No método desenvolvido por Joseph Pilates identificamos preocupações que vão além de ordens puramente cinesiológicas, mas que estão presentes na execução dos exercícios com foco mais amplo, podemos chamar de estéticos, ocupando a esfera do sensível. Portanto a prática do Pilates permite a capacidade de integração dos estados de consciência e relação com o meio, ultrapassando a mera execução física ${ }^{9}$.
Um corpo livre de tensão nervosa e de cansaço excessivo é o abrigo ideal oferecido pela natureza para manter uma mente bem equilibrada, que é sempre capaz de enfrentar com sucesso os problemas complexos da vida moderna ${ }^{10}$. Segundo Pinton e Franco ${ }^{11}$, os benefícios que o método proporciona são diversos, variando entre a melhoria da flexibilidade, melhoria da postura, reeducação postural, dentre outros. No entanto, o maior benefício verificado é à redução do estresse.

\section{As possibilidades do Corpo}

É importante ressaltar que o sujeito domina o seu próprio corpo, visto que o corpo trata-se de uma matéria modelável, capaz de mudar e de evoluir. No entanto, sabe-se que essa capacidade de domínio pode estar intimamente ligada a vários fatores, não somente hereditários, mas também fatores fisiológicos, sociais e psicológicos ${ }^{13}$.

A partir da análise das falas é notório que os entrevistados concordam que as práticas corporais são resultadas do binômio corpo-mente. O corpo é um reflexo da mente, e sendo a concentração um dos princípios do Pilates, os praticantes puderam notar a influência da mente sobre o corpo ao concluírem exercícios em que imaginavam não conseguir.

Antigamente, a relação entre a mente e o corpo era vista de forma dualista, independente uma da outra, no entanto, com passar dos anos a Psicanálise começou a estudar esses fatores de forma conjunta e dinâmica. Dessa maneira, estudiosos tentaram explicar as inter-relações entre os aspectos emocionais e as manifestações somáticas e, embora não haja um consenso sobre o tema, concorda-se que existe uma relação entre eles ${ }^{14,15}$.

É de suma importância pensar sobre o corpo de acordo com os seus movimentos, assim como pensamos no esporte, na ginástica, na dança como práticas corporais. O corpo também representa uma linguagem participante da vida social, na construção de saberes e valores, representando os comportamentos e as relações humanas ${ }^{16}$. 
Além disso, diante da vasta dimensão das possibilidades do corpo, tem-se a ideia do corpo biológico, e a importância de cuidar de si mesmo para ter um bom desempenho nas atividades propostas.

A associação do corpo saudável com o viver bem abrange das mais simples às mais complexas ações. Os sujeitos ao se referir aos seus corpos no sentido da saúde como liberdade e independência, geralmente evidenciam a importância de um corpo saudável para a autonomia do ser humano. Percebe-se que a saúde é responsável pelo bem-estar e felicidade, proporcionando aos seus corpos conforto e alegria em viver bem ${ }^{7,18}$.

Considerando esses relatos e as discussões aqui tecidas, que foram indubitavelmente enriquecidas por sua análise diante dos dados disponíveis na literatura, é possível afirmar que atividades como esta, que evidenciam o corpo, colaboram para o aprendizado e autoconhecimento daqueles que o praticam.

\section{Conclusão}

Conclui-se então que o presente estudo conduziu às reflexões sobre o corpo e sua relação com o aprendizado, visto que, o projeto de extensão baseado no método Pilates contribuiu positivamente para o conceito e percepção de corpo dos acadêmicos do curso de fisioterapia, de foi possível obter diversos aprendizados com as experiências corporais praticadas como a autopercepção do corpo, o autocuidado, a integração do corpo e da mente, além de conhecer as possibilidades que o corpo pode desenvolver, bem como os limites que pode alcançar. Todavia, faz-se necessário que sejam realizadas novas pesquisas sobre esta temática, relatando novas experiências e contemplando amostras mais amplas com participantes mais diversificado.

\section{Contribuições dos autores}

Souza SMO participou da concepção, delineamento, busca e análise qualitativa dos dados da pesquisa, interpretação dos resultados e redação do artigo científico. Oliveira BC participou da coleta dos dados da pesquisa e da interpretação dos dados. Silva CS, Souza LGLP, Da Silva VMS participaram da coleta dos dados da pesquisa. De Paiva SSC participou da interpretação dos dados e revisão do artigo científico. Torres MV participou da concepção, delineamento e revisão do artigo científico.

\section{Conflitos de interesses}

Nenhum conflito financeiro, legal ou político envolvendo terceiros (governo, empresas e fundações privadas, etc.) foi declarado para nenhum aspecto do trabalho submetido (incluindo mas não limitando-se a subvenções e financiamentos, participação em conselho consultivo, desenho de estudo, preparação de manuscrito, análise estatística, etc.).

\section{Referências}

1. Cordás TA, Castilho S. Imagem corporal nos transtornos alimentares: instrumento de avaliação: body shape questionnaire. Psiquiatria biológica. 1994; 2 (1):17-21.

2. Schilder P. A imagem do corpo. Buenos Aires: Paidós;1997.

3. Nogueira QWC. Educação física e pedagogia crítica:praticar o discurso? Perspectiva. Florianópolis. 2001;21(01):179-197.

4. Bomfim Z. Corporeidade e vivência: existe espaço na educação universitária. Revista de Educação Aec. 2000; 29 (116): 71-81.

5. Corrêa L. Corporeidade no ensino fundamental de jovens e adultos: como área de conhecimento e como linguagem. Revista Aprendendo com Jovens e Adultos. Porto Alegre. 1999; 1: 67-81.

6. Souza TM. O método pilates solo na educação física: alguns benefícios. [Monografia]. Florianópolis: Universidade Federal de Santa Catarina;2012.

7. Pires DC, Sá CKC. Pilates: notas sobreaspectos históricos, princípios, técnicas e aplicações. Revista Digital. Buenos Aires2005;10(91). 
8. Muscolino JE. Cipriani S. Pilates and "powerhouse" i. Journal of Bodywork Movement Therapies. 2004;8:15-24. doi: 10.1016/ S1360-8592(03)00057-3

9. Pilates JH, Miller WJ. Return to life through contrology. 2nd ed. New york: Presentation Dynamics; 1998.

10. Kolyniak Filho C, Garcia IEG. O autêntico Método Pilates de condicionamento físico e mental: (contrology): contribuições para uma fundamentação teórica. 2.ed. Stampato. São Paulo; 2012.

11. Pinton LB, Franco ACSF. Influência do Método Pilates. Coleção pesquisa em Educação Física. São Paulo. 2007;5(1):345-350.

12. Martins MJS. Corpo em movimento: relações entre processo criativo e produção de conhecimento. [dissertação]. São Paulo: Universidade Estadual de Campinas, Faculdade de Educação, Campinas, SP; 2014.

13. Mauss M. As técnicas do corpo. In: mauss, marcel. Sociologia e antropologia. Cidade:ubu editora Itda - me; 2018.

14. Valente GB, Rodrigues AL. Psicossomática e Psicanálise: uma história em busca de sentidos. In: anais do XVII Congresso Brasileiro de Medicina Psicossomática. Porto Alegre; 2010.

15. Cruz MZ, Pereira-Júnior A. Corpo, mente e emoções: referenciais teóricos da psicossomática. Rev Simbio-Logias. $2011 ; 4(6)$.

16. Brasileiro LT, Marcassa LP. Linguagens do corpo: dimensões expressivas e possibilidades educativas da ginástica e da dança. Pro-posições2008; 19(3):57. doi: 10.1590/S010373072008000300010

17. Moscovici S. Investigações em psicologia social. 9.ed. Vozes; 2003.

18. Silva SED, Padilha MI, Rodrigues ILA, Vaconcelos EV, Santos LMS, Souza RF, Conceição VM. Meu corpo dependente: representações sociais de pacientes diabéticos. Rev Bras Enferm. 2012;63(3):404-9. doi: 10.1590/50034-71672010000300009 